\section{Marginalia and Marginal Figures in the Romantic Age}

Alex Watson, Romantic Marginality: Nation and Empire on the Borders of the Page (London: Pickering \& Chatto, 2012)

Simon P. Hull, Charles Lamb, Elia and the London Magazine: Metropolitan Muse (London: Pickering \& Chatto, 2010)

The two books under review are in many ways comparable. The authors of both represent a younger generation among the students of the romantic era. Both of them practice a scholarship that is historically grounded and is interested in the material aspects of literary production. Hence, both studies have been published in Pickering \& Chatto's The History of the Book series (where "the book" metonymically stands for all tangible conveyors of culture, including journalism). Both of them are interested in the rethinking of the canon, and neither of them sees the "greater romantic lyric" as the only possible candidate for its single centre. Both are interested in romantic prose writing. However, while Watson investigates how marginalia reflect or reject contemporary thinking about the margins of the British Empire,

The views expressed in the book reviews do not necessarily reflect the opinions of the editors of The AnaChronisT.
Hull looks at its very centre, albeit from the perspective of a self-consciously marginal figure, Charles Lamb's Elia.

Alex Watson's Romantic Marginality: Nation and Empire on the Borders of the Page is an important book, because it is the first book-length attempt at investigating romantic authors' practices of annotation. As the title indicates, the innovative approach is connected to post-colonial studies. Watson argues that the way marginal texts (footnotes and endnotes mostly) are used reveals a lot about attitudes concerning centre and margin in the growing empire.

The first chapter gives a short but very fascinating overview of the development of what Watson calls the "subtle cultural anxiety about the potentially encroaching effects of paratexts" (13), which he sees as a neglected factor in the emergence of the Romantic concept of the work of art as an organic whole (poems, according to John Keats, "should do without any comment," 29). The eighteenth century saw many objections to annotation. From theology ("the word of God," said Berkeley "should not need a comment," 16) to the debate between Ancients and Moderns, in which Pope compared the presence of commentaries in texts by Shakespeare or Milton to “ 'Hairs, or straws, or dirt, or grubs, or worms' preserved in amber" (17). Thus, a distinction came to be made between the "pedant," who simply collects information (and transforms it into footnotes), and the critic of sensibility, who directs the readers' attention to "beau- 
ties and blemishes" in a given text. At the same time, the eighteenth century sees a rising interest in the potentials in annotation, on the one hand for purposes of Scriblerian parody and satire, as in "A Tale of a Tub" or the Dunciad Variorum, and on the other, for using real footnotes in experimental ways (Watson quotes a few of what Winston Churchill referred to as "Gibbon's naughty footnotes," 24).

The second chapter deals with "struggles for authorial ownership and interpretative hegemony" (32) as witnessed by marginalia. An extreme example of this is provided by William Beckford's Vathek (1786), a novel originally written in French, and then translated into English and provided with a commentary by clergyman and schoolmaster Samuel Henley. Henley took his task so seriously that he not only provided many more footnotes than was thought necessary by Beckford, but actually published the English edition without any mention of the fact that he was not the author. A more subtle, and better known, example is the case of Wordsworth and Coleridge's Lyrical Ballads, where the notes not only conduct a dialogue with the readers, but also a more private conversation and contest between the contributors over the meaning of the texts.

Watson chooses the example of Thomas James Mathias's notes for The Pursuits of Literature (1794-7) as an example of a romantic poet using his comments to ensure that his poem takes part in rich public interactions with the wider world.
The very informative discussion, however, made me feel - not for the last time - that the line of argument could have taken exactly the opposite direction as well. The fact that direct political attack can (only) take the form of a footnote might also reveal anxiety about romantic poetry's ability to enter the public arena.

It is in chapter 3 that Watson finally finds his true subject: the similarities and differences between political and textual marginalisation. The chapter includes analyses of Maria Edgeworth's Castle Rackrent (180o) and Sydney Owenson's The Wild Irish Girl (1806), with special attention to the footnotes, of course, which "manifest their authors' dual marginality as Irish women writers" (49). Indeed, Watson posits a recognisable late eighteenth century feminine tradition of marginalia, exemplified by works such as Charlotte Smith's Elegiac Sonnets or "Beachy Head," Mary Wollstonecraft's Vindication of the Rights of Woman and Charlotte Brooke's Reliques of Irish Poetry. The similarities are not immediately noticeable. While, according to Watson, the significance of Smith's notes is that she "demonstrated her mastery" of "hitherto male-dominated discourses" (51), Wollstonecraft's are seen as "provocatively unscholarly," the first demonstrating anxiety about women's place in public discourse, the second its opposite. What makes them all feminine, though, is that they use the margins to "put forward emotional pleas” (57). Castle Rackrent 
is unique because it breaks with this tradition, which also puts Edgeworth on the imperial side of the question: her notes associate native Irish customs with backwardness and barbarity. Owenson, however, uses the antiquarian learning gathered in the notes to The Wild Irish Girl "as evidence of a distinctive Irish national identity" (65), and thus as possible "foundation for the nation's future" (64); in effect, she constructs "an anti-colonial archive" (68). By focusing on what the English reader is ignorant of, the notes to both novels, although to differing degrees, undermine the coloniser's sense of superiority.

Watson interprets Robert Southey's commentary accompanying Thalaba the Destroyer (1801) as the opposite of an "anti-colonial archive"; he calls it "an imperial collection," which is based on "the practice of extracting objects from their original context, and resituating them in the hermetic - 'useless' - world of the collection" (73). That this text should receive such a detailed interpretation is perhaps going to be surprising to some people; some of us might even snigger that it is no wonder that Watson does not focus on the centred text, but he still establishes certain interesting parallels between the frenzied collecting zeal of the Empire and Southey's "miserlike love of accumulation" (73, the poet's own words). The British attempt was to establish London as the centre not just of finance and power, but also of knowledge, thus marginalising the colonised lands in a cultural sense as well.
Southey is also a good example of how notes begin to live a life of their own. He insisted that his "notes will be too numerous and too entertaining to print at the bottom of the page," which enables us to imagine a type of reader (maybe not even too rare a species) who actually is more interested in the notes than in the poem itself. Watson relies on Edward Said's insight that Napoleon's occupation of Egypt (1798), a military campaign where the army was accompanied by 165 scientists, artists and other intellectuals, created a very strong precedent for an association between imperial expansion and intellectual progress. Watson argues that while Southey very much shares and even propagates this "progressive" view of imperialism, his fascination for the supernatural in Thalaba makes it difficult to assimilate him to the "Enlightened" view. Moreover, not even in the notes, where one would normally expect it, does the rationalisation of the superstitious elements take place. Room is left for the possibility, in other words, that Southey is more open to non-Western ways of thinking than he is usually given credit for, maybe in this poem "truth is dependent on social circumstances" (95). Watson makes a similar statement about The Curse of Kehama (1810), where India appears as a "disturbing and fascinating alterity" (98). It remains a question, however, whether delight in the wildly exotic really amounts to openness towards "alterity." In certain parts the mixture of eastern and western 
in the poem struck me as simply silly ("Allah, thy will be done" (I.7) and the rest of it). Nevertheless, Watson is surely right to stress the importance of Southey's poems in founding a recognisable tradition of narrative poetry in the romantic period, which includes works by Thomas More, Felicia Hemans, Lord Byron, and P.B. Shelley, many of which share the fascination with the eastern and the exotic.

Chapter 5 turns to Scotland, and its two best-known authors: Robert Burns and Walter Scott, who both "translate Scots and Gaelic dialect terms, collect, display and remake materials from Celtic and Pictish folk traditions, and gather and interpret anthropological information about Highland and Lowland communities" (101), and thus "in their annotation, Burns and Scott created archives of history, culture and tradition from which a Scottish identity could be formed" (103). Watson emphasises that "to be a Scots poet" for Burns, as much as for previous authors like Robert Fergusson or Allan Ramsay, was "to live a bilingual existence, on the margins between Scotland and England" (105). But exactly because of the complexity of the cultural interchange that their work achieves, it is far from obvious whether the archival work embodied in the annotation actually "decentres the English metropolitan reader, confronting them with their lack of cultural competence in an alien environment" (106), or rather decreases and domesticates the otherness of that environment. Nevertheless,
Watson is surely right to elaborate on the importance of Burns's writing in the Scottish dialect as opposed to the distinguished tradition of scholars (such as Adam Smith, David Hume or Hugh Blair), who simply eliminated Scots (Although here as well some reflection on differences of genre and the possibilities of linguistic experimentation would have been beneficial to the argument). Ultimately, Burns' annotations are seen as deconstructing the English-Scottish dichotomy on which the negative discrimination of the latter could otherwise rest.

Walter Scott's historical novels, however, effect a union (almost the Union) by "distancing the reader from ... diversity, presenting cultural differences as evidence of past conflicts that have been superseded by the civilising effect of national centralization and modern manners" (108). It is only on the margins that Scott gives voice to the trauma that accompanies the history of integration. From the first, Scott's strategy is to record (already in his ballad collection and early poetry) the brutality of the past, and to enable the reader to sense the advance that has been made since then. As most of the violent acts are connected to the fight against English supremacy, however, the very bases of British rule are represented as bloodstained. Scott appears as an ethnographer in the footnotes, elaborating on the wider cultural significance of what might otherwise be seen as mere couleur locale. 
Having examined the contradictory strategies of the two most famous Scottish writers of Romanticism, Watson turns to Lord Byron, whom he calls, with dazzling overstatement, "their fellow Scotsman" (116). In this last chapter the analysis centres on Byron's and John Cam Hobhouse's imperfectly collaborative annotations to Childe Harold's Pilgrimage (1811-16). Although the post-colonial perspective does not at first seem to be as clearly relevant as in the case of the Scottish writers, general problems related to imperialism are at stake here as well; most famously in the case of Byron's objection to the transferral of the Parthenon sculptures to London. Byron's footnotes contain much information about the places Childe Harold visits, and by insisting on the immediacy and authenticity of his firsthand experience, he allows his readers to see through the widespread ideological accounts of these colonised cultures, and thus "to comprehend the world from the perspective of the margins" (124). Hobhouse wrote the notes to Canto IV, and Watson offers a very interesting reading of the text as a result of a complex, uneasy cooperation between the two friends, in which the footnotes provide the crucial context for placing the Byron of this Canto in the line of republican Italian poet-heroes. He does not, however, make a very strong case for either of the two actually thinking of this as creative cooperation, or for the work ever having been read in that way in its history of reception, or indeed examine how many people actually worked their way through the ocean of Hobhouse's annotation. Watson uses this final example as a summary of many of the themes of his book, and indeed Watson's reader will by this point be ready to share in the pleasures of the de-centred text that delights in heterogeneity and non-hierarchical variety.

I have found the Conclusion ("Romantic Marginality and Beyond") to be the least satisfying part of the book. Most of the short chapter is taken up by a seemingly ad-hoc list of works from $\mathrm{J}$. F. Cooper to David Foster Wallace, in which notes are also used in creative ways, and to which some of the insights of the book seem to be applicable. I would, however, have wished for a chapter that meditates on how far we can generalise from the case studies in the volume. By this point, we have seen that annotations can complicate the meaning of a text in innumerable ways, we have seen them caught up in widely different ideologies, we have seen them as sociable and as satirical, playful and (pseudo)scholarly. Is there a way in which a taxonomy can be drawn up? Are there any deductions to be made as to the conditions of possibility in which a set of marginalia assumes significance in one way or another? What factors influence the process? Watson mostly examines the annotations in the works of moreor-less solitary authors (or in some cases of duos), but surely facts of publishing and formatting, as well as of recep- 
tion, are also significant. "I have opted to focus on how authors use annotation, rather than what these practices reveal about the nature of reading in the period" (2) Watson claims in "his Introduction," but it is debatable how far the two can be separated. He, for instance, regularly makes assumptions about how the dialogue between centred text and marginalia influences the reader, typically without offering empirical evidence of this actually manifesting itself in reception history. Contemporary reviews are regularly cited at the beginnings of analyses, but not much is made of them to this effect.

Another problem with the "Conclusion" is that reading through the list of texts from different periods, we become uncertain how far this project is historically specific at all. Surely, if the context in which the texts are examined is the troubled relationships between colonial centre and the peripheries, then it has to preserve a high level of historic specificity (since those relationships were themselves unstable). Nevertheless, given that Watson's interpretations are relatively easily divested from the contexts of the histories of reading, cultures of publication, reviewing, one gets the sense that what we are faced with are deconstructions of the centremargin dichotomy, and rather brilliant ones at that.

So while I agree with Tom Williams, who in a $T L S$ review celebrates the book as groundbreaking, ${ }^{1} \mathrm{I}$ believe that if the study of romantic marginality wishes to become a well-established field in present day romantic scholarship, it needs to reflect more on its methodologies, and needs to engage more with studies of readers' marginalia (especially those of H. J. Jackson), ${ }^{2}$ and, in general, move away from the examination of the solitary author to the social scene of writing. In this Watson's work, which certainly succeeds in directing attention to the margins, will be fundamental. It makes us understand that there is more to the footnote then what Anthony Graft called the Cartesian tradition of clarity and distinctness. ${ }^{3}$

Simon P. Hull's Charles Lamb, Elia and the London Magazine argues for a reconsideration of the Elia-essays that takes into consideration their specifically metropolitan character, and their position in what Hull calls "periodical text," two subjects against which traditional romantic scholarship tended to be biased. ${ }^{4}$ Although Hull often refers, in a very broad sense, to the "periodical text," it is the work of Lamb's great prose-writing colleagues (William Hazlitt, Leigh Hunt, Thomas de Quincey and to a lesser extent Pierce Egan) that provides the backdrop for the analysis. By this, Hull also counters the commonplace objection that Elian writing equals escapism. As Felicity James argues in her review of the book, Hull goes beyond existing scholarship on Romantic magazine culture, by focusing on the development and the complexity of the Elia character. ${ }^{5} \mathrm{He}$ also places the traditionally marginal genre of the essay at 
the very heart of the literary scene. The complex argument is that while Elia is part and parcel of the commercial world of the London Magazine, the essays also cunningly educate the middle-class reader "to see beyond the material and the empirical" (15).

The first chapter argues that "an Elian mode of metropolitanism emerges in response to the 'anxious' image dramatised by the Cockney dispute” (20). In Hull's usage, the very word "Cockneyism" refers to the "professional anxiety" (22) caused by the (not complete) anonymity and the commercial and collaborative nature of writing for magazines. Hull quotes a variety of contemporary periodical writers (but especially Hazlitt) who display this anxiety by selfcriticism, saying that "the only way for the genre" of the embattled periodical essay "to redeem any literary credibility is for it to attack itself" (26). Another option, I think is to tap into the perfectly respectable eighteenth century traditions of essay writing. In a book that claims, in the very first sentence, to be "about the essay" (1) I would have expected more about this. Hull could, I think, have made more of Hazlitt's lecture "On the Periodical Essayists" (from a course delivered in the winter of 1818/1819) and his Edinburg Review essay, “The Periodical Press" (1823) with the rather well-known rhapsody, "let Reviews flourish - let Magazines increase and multiply - let the Daily and Weekly Newspapers live for ever!"; 6 in neither case are the signs of anxiety immediately visible. Hull's point about Elia is a very important one, however. Lamb becomes a successful writer partly by his ability to turn weakness into strength: to create a character that is forever elusive, layered and detached, even from himself. Elia is also distanced from the intense critical debates of the time, and achieves a certain amount of ideological neutrality.

The re-education of the readers, moving them away from the rigid, insensitive criticism exemplified by the Cockney controversy takes the form of "manoeuvring" their "judgmental tendencies into corrective selfreflection" (40), often by exposing himself to such criticism ("Poor Relations," or "The Convalescent" could, Hull suggests, be read along these lines). The harsh opinions expressed in "Imperfect Sympathies" are defended as expositions of the inevitable bias and partiality of any act of critical judgement. Through their very arbitrariness, they stand as a plea for toning down such attacks, typical amongst other things of the namecalling that resulted in the labels by which we still identify different versions of romanticism (Jacobin, Lake, Cockney). Against such finger pointing, "Elia adopts a playful, suggestive, nevernaming style" (50).

The second chapter examines the Elia essays in the context of that most talkedabout figure of metropolitanism, the flâneur. Coleridge's “This Lime Tree Bower my Prison," a poem that builds upon the contrast between enclosure and 
free movement (and to which Lamb objected), and also the beggar poems of Wordsworth are read as articulating a "liberalist association of vagrancy with freedom" (58). Beggars are also present in the essays, in fact, Elia at one point claims that the beggar is "the only free man in the universe" (58). Nevertheless, this freedom is tied to being fixed, immobile, crippled, a fate that in many ways the lame figure of the essayist, chained by everyday office routine, also shares. Rural liberty is out of the question here. The most important claim of this book is put forward in this context. These acts of selflimitation so often classify the Elian model as a lesser, incomplete Romanticism. 7 The motivation for this has, of course, been largely biographical: the well-known tragedies of the Lamb family as well as the personal responsibilities of Charles have typically been seen as impediments in the way of his becoming a great romantic author. Hull, who rarely resorts to biographical explanations, claims that if we see metropolitan Romanticism as not lesser, simply different, then we can see Lamb's art of essay as complete and altogether glorious.

Hull offers a reading of "Witches and other Night-Fears" (1821) as an example of how Elia's self-imposed limitedness emerges as power. The very list of what Elia is incapable of (vision, dreaming, transforming the experience of terror and of the sublime into art) actually defines a different and original poetics. "The familiar, domesticated city in which Elia's place as a prose writer is established" (77) is set in opposition to the more poetical but less substantial, less solid visions of De Quincey's “dream cities" as well as to "Wordsworth's fantastic city in Book II of The Excursion" (76). I find the brief comparison with the fellow-metropolitan, Leigh Hunt very much worth pursuing further, yet I am also reminded that Elia's "ultimately knowable city" (82) is a tiny fragment of the actual metropolis, of which "the absence of all forms of pedestrianism" (80) in the essays is surely an indication. Nevertheless, I find the idea that the spatially limited Elia transforms urban ambulation into a form of writing (reflecting what Hull calls an "epistemological ramble," 82) quite brilliant.

The third chapter focuses on the essays that describe Elia's vacations away from London. Once again, Hull sees Lamb as going further than Hazlitt, whose "On Going a Journey" presents relief "from the intense sociability of life in the metropolis" (105). For Hazlitt, the meaning of rural liberty is dependent on the metropolis, but in the Elia essays not even Hazlitt's temporary relief is allowed. In "Mackery End, in Hertfordshire" (1821) even though Bridget's "regressive" (107) ruralising is painted in endearing tones, Elia does not experience such a holiday-long "return to nature." The dilapidated country-house, the very seat of the Gothic, here represents "a distorted image of the familiar, a staple feature of the essay" (108). Further, this distortion is constantly connected to dreams, from which "Elia 
awakes into the stable domestic reality of his London home" (113): waking up from the rural dream is clearly presented as liberation. Not "in great City pent," not him! The city and the metropolitan writer appropriate the country, not the other way round.

Chapter 4 examines the description of the urban poor and especially the beggars in the context of the debates surrounding the Poor Law, and the activity of the London Society for the Suppression of Mendicity. Here, for once, Lamb appears to occupy a similar position to those of his poetic contemporaries, Blake and Wordsworth. In his analysis Hull produces the most powerful case I am familiar with for reading essays such as "The Praise of Chimney-Sweepers" or "a Complaint of the Decay of Beggars in the Metropolis" not as heartlessly aestheticising treatments of the darkest aspect of metropolitan life, but as engaging with this central debate of the age, although in a characteristically roundabout way.

Like Wordsworth, Elia is concerned that systematic attempts to eradicate mendicancy only destroy the fabric of a community, but he disagrees in that for him urban life is not the threat, but the very network of personal connections that is threatened by the reformists. Lamb knew Blake's Songs (including the two "Chimney Sweepers") and shared their revulsion from the psychology of "pity" as patronising and impersonal. In Hull's reading, Lamb avoids the sentimentality of pity "through an appropriation of Hogarth's carnivalesque style to a celebration of supposedly low, plebeian life" (134). He shows chimney-sweepers or beggars not as helpless objects of pity, but in situations of power. The unexpected laughter of the sweep represents a moment when the world turns upside down; like the traditional coronation of the Cockney king and queen; the urban poor are shown as dominant, bursting with joie de vivre.

The last chapter focuses on the theatrical world of the essays, and the role that Elia most likes to play on the great stage of the metropolis, that of the fool. Hull points out how, after the distinctly antitheatrical views expressed in Lamb's vastly influential early paper "On the Tragedies of Shakespeare” (1811), the Elia essays embody a distinctly theatrical practice. (Although I think he should have talked about the Elian "On the Artificial Comedy" as well, where the concept of comic theatre is more immediately relevant). The early essay on Shakespeare suggests that while reading is a creative, interpretative process, watching dramatic spectacles is not. The Elia essays presuppose a reader who moves about London with the detachment of a theatregoer, but they try to seduce him or her into actively looking at specific sights or individuals and engaging in acts of attention and even charity. Thus, Hull argues, Lamb, unlike Hazlitt, Hunt or Coleridge, moves beyond his early anti-theatrical stance to embrace a readerly theatricality. Clowning too, as a role, is based largely on Lamb's beloved comic performers (like Munden). Keep- 
ing a safe distance from actual madness, this allows for the creation of a second self, an elusive identity to be acted out in front of the metropolitan reader.

The book closes with a suggested reconsideration of the identity of the author, not as a lonely figure involved in heroic struggle against precursors (à la Bloom), but as a figure of urban sociability, the artist of language that is seen as by its nature, dialogical. In this context, Lamb emerges as neither marginal, nor minor, but as a par excellence author.

Bálint Gárdos

\section{Notes}

1. Accessed 2 November $2012<$ http:// www.the-tls.co.uk/tls/reviews/other categories/article1157920.ece>.

2. H. J. Jackson, Marginalia: Readers Writing in Books (New Haven and London Yale University Press, 2001), and especially his Romantic Readers: The Evidence of Marginalia (New Haven and London: Yale University Press, 2005)

3. Anthony Grafton, The Footnote: $\mathrm{ACu}$ rious History (Cambridge, MA: Harvard University Press, 1999), pp. 190-222.

4. Unaccountably, he makes no reference to Gerald Monsman's Charles Lamb's as the London Magazine's "Elia” (Lewiston, NY: Edwin Mellen, 2003), which reprints some of the magazine texts and offers insights into the ways in which Lamb changed them for the collected edition.

5. Felicity James, [untitled review], The Byron Journal, 38.2 (2010) 192-193.

6. P. P. Howe, ed., The Complete Works of William Hazlitt. 21 vols. (London: Dent, 1930-4). Vol. 16, p. 220.

7. Most importantly in the late Thomas McFarland's influential Romantic Cruxes (Oxford: Clarendon Press, 1987).

\section{The Quest of the West - Heroes of Transformation}

Peter Whitfield, Travel: A Literary History

(Oxford: The Bodleian Library, 2011)

It is a much-needed break from discourse oriented literary considerations to let such books as Whitfield's Travel have a considerable intellectual impact. Finely illustrated and bound, it is an adventure narrative, a natural history, an overview of the roving Western mind, and an account of 4500 years' narratives of geographical movement from within the Mediterranean, Europe, and America. Travel literature as a genre, as the author points out, is in constant formation, open to theory but also exact in its historical and cultural relevance. The author manages to balance his work between academia and artful entertainment, without bias or didactic message but with quantities of wondrous diversity categorized into neat stages of a suggestive larger scope. The historically sequential chapters lead from religious deliverance through political tyranny to global ecology. The style of the book is light and elegant, simple and clear. Whitfield evokes much more than he claims, a vision beyond correct listing and cataloguing, where different genres and disciplines merge to reconnect semiotic elements. His cases of travel writers are linked not simply through the common genre and chronology, but through a single aspect: how travel writing relates to human conditioning. The 